\title{
FERREIRA DE CASTRO: DOS ARQUIVOS PESSOAIS COMO PARATEXTOS LITERÁRIOS
}

Adriana Aguiar ${ }^{1}$

RESUMO: A questão que se coloca neste texto é pensar como se construiu a imagem do autor português Ferreira de Castro e como essa imagem permeia leituras críticas que se têm feito de sua obra. Em outras palavras, trataremos de um problema implicado nos estudos acerca da obra do autor, o problema da representação dos arquivos pessoais: textos que não raramente encaminha(ra)m o leitor ao entendimento da obra ficcional, especificamente de $A$ Selva, como um relato verídico, um documento antropológico, um manifesto socialista e até mesmo como um espelho que reflete a vida daquele que escreveu o romance. Recorremos ao que Gérard Genette conceitua como "paratextos" para sugerir por que o problema da representação se tornou proeminente nas leituras que se têm feito dos romances do autor português.

PALAVRAS-CHAVE: Ferreiras de Castro; Biografia; Arquivos; Crítica literária.

\section{FERREIRA DE CASTRO: FROM PERSONAL ARCHIVES AS LITERARY PARATEXTS}

\begin{abstract}
The question that we enquire in this text is to think about how the Portuguese author Ferreira de Castro's image was built and how this image goes through the critical readings which have been done about his work. In other words, we are going to deal with an issue involving the studies on Castro's work, the issue related to the representation of the author's personal archives: texts, which, not rarely, lead or led the reader to the understanding of a fictional work, specifically of $A$ Selva, as a true report, as an anthropological document, as a socialist manifest and even as a mirror that reflects the life of that who wrote the novel. We used what Gérard Genette defines as "paratexts" in order to suggest the reason why the issue of representation became prominent on the readings that have been done on this Portuguese writer's novel.
\end{abstract}

KEYWORDS: Ferreira de Castro; Biography; Archive; Literary critique.

\footnotetext{
1 Aluna do Programa de Pós-Graduação em Letras, Estudos Literários, na Universidade Federal do Amazonas, bolsista da Fundação de Amparo à Pesquisa do Amazonas (FAPEAM).
} 
Tenho sobre a mesa de meu computador uma biografia de Ferreira de Castro, cuja capa é ilustrada com um retrato do escritor. Distancio-me da imagem e trago à memória os autorretratos de Van Gogh, artista que usou o próprio corpo como matéria da arte, incluindo um episódio de mutilação da orelha. Noto que o pintor impressionista fez vários retratos de si, mas, em todos eles, a face aparece diversa: múltiplos de um mesmo eu. Retorno à biografia de Castro e uma pergunta me instiga: o que é um retrato? Uma imagem fiel ou uma edição que marca um momento específico do eu? A questão que se coloca neste texto é, então, pensar como se construiu a imagem do autor português e como essa imagem permeia leituras críticas que se têm feito de sua obra. Em outras palavras, tratarei de um problema implicado nos estudos acerca da obra de Castro, o problema da representação dos arquivos pessoais do autor: textos que não raramente encaminha(ra)m o leitor ao entendimento da obra ficcional, especificamente de $A$ Selva, como um relato verídico, um documento antropológico, um manifesto socialista e até mesmo como um espelho que reflete a vida daquele que escreveu o romance. Recorro ao que Gérard Genette conceitua como "paratextos" para sugerir por que o problema da representação ${ }^{2}$ se tornou proeminente nas leituras que se têm feito dos romances do autor português.

Antes de nos atermos aos arquivos de Ferreira de Castro, é oportuno chamar atenção para textos do início do século XVI (como "A Carta" de Pero Vaz de Caminha) e para o entrelaçamento entre documento (arquivo que contém em si o real) e ficção, uma vez que, antes mesmo da fundação do que se denomina sistema literário brasileiro ${ }^{3}$, há um elo entre narrativa histórica, narrativa pessoal, imaginário e literatura, que persistirá na produção crítica atual. Refiro-me à literatura de viagem, no âmbito da qual não é possível classificar as cartas dos viajantes apenas como narrativas literárias, nem unicamente como documentos históricos. Questão antiga nos debates teóricos, é exatamente esse problema que Terry Eagleton expõe na introdução do livro Teoria da Literatura (2003): o que determina que um texto deva ser lido como literário ou não? No caso específico de $A$ Selva, tem-se, mais uma vez, um relato de um viajante, de um europeu que de fato viveu na

\footnotetext{
${ }^{2}$ Representação em duplo contexto: 1) dos arquivos pessoais; e 2) da realidade, que se insinua real justamente pelo estatuto de verdade que o primeiro contexto confere ao segundo.

${ }^{3}$ Em Presença da Literatura Brasileira: história e antologia (1992), Antonio Candido e José Aderaldo Castelo chamam atenção para a importância da literatura de informação, como aquela que portava o germe do nativismo, caráter fundador da vindoura Literatura brasileira. Já em História da Literatura Brasileira, Luciana Stegagno-Picchio, fazendo referência aos textos dos cronistas portugueses afirma que estes "[...] têm para nós o interesse de escrever numa língua que será depois a do país. Nesse sentido, seu depoimento não será apenas um documento, mas ele funcionará como elaborador e fixador de tópoi estilísticos destinados a alimentar as futuras letras brasileiras" (2004, p. 75).
} 
Amazônia, que experimentou a rotina nos seringais da borracha e, nesse mesmo período, dava os primeiros passos no universo da criação literária. E parece ser exatamente o conhecimento empírico do autor, o qual tece uma ficcionalização do real experimentado por si mesmo, que desestabiliza o leitor e o encaminha para buscar na metáfora ${ }^{4}$ do texto literário a realidade.

No livro Paratextos editoriais (2009), Gérard Genette estuda o aparecimento e o desenvolvimento de gêneros textuais que ele denominou "paratextos". Segundo o teórico, o texto "raramente se apresenta em estado nu, sem o reforço e o acompanhamento de certo número de produções, verbais ou não, como um nome de autor, um título, um prefácio" (p. 9). Tais produções visam chamar a atenção para a obra e situam-se numa região ambígua, ou seja, estão ao mesmo tempo dentro e fora do texto, influenciando o leitor na maneira como perceberá o escrito e o relacionará numa rede textual ampla. Deste modo, afirma Genette, “o paratexto, sob todas as formas, é um discurso fundamentalmente heterônomo ${ }^{5}$, auxiliar, a serviço de uma outra coisa que constitui sua razão de ser: o texto" (p. 17). Os paratextos possuem, portanto, uma força ilocutória ${ }^{6}$ que atua sobre o leitor, construindo representações do autor, da obra e do contexto, instaurando um sistema de crenças e valores que orientam a forma como o texto será recepcionado. Os arquivos que se vinculam a Ferreira de Castro podem ser entendidos, neste sentido, como uma composição paratextual, capaz de engendrar uma leitura hibridizada: entre um eu vivido e um eu ficcionalizado, leitores e críticos literários, com alguma frequência, não conseguem diferenciar ou apartar as fronteiras.

Experiência e linguagem, reforçadas pelos paratextos, caminharam lado a lado com as publicações do escritor português. Jaime Brasil, em 1961, ao biografar o autor acentua o peso das vivências na sua formação enquanto escritor. Retoma a infância do menino de Ossela, cidade pequena de Portugal, relatando que este não teve contatos com livros e que sua carreira escolar não passou do primeiro ano. Os únicos textos que Castro leu antes de tornar-se um escritor, segundo o biógrafo, foram os livros escolares e alguns folhetos que o menino via na feira. Analisando pela perspectiva do adolescente com quase nenhum estudo

\footnotetext{
${ }^{4}$ Sobre a metaforização do real Eneida Maria de Souza argumenta: "metaforizar o real significa considerar tanto os fatos quantos as ações praticadas pela pessoa biografada como possibilidade de inserção na esfera ficcional" (2011, p. 54).

${ }^{5}$ Sujeito a leis exteriores ou à vontade de outrem.

${ }^{6}$ Conceito desenvolvido por Austin e Searle, refere-se ao valor de que se reveste um enunciado. Segundo os autores, os atos ilocutórios consistem numa espécie de ações - realizadas por um locutor através de um enunciado - que visam, intencionalmente, obter algo do alocutário.
} 
regular, de poucas leituras, portanto, excluído de uma tradição literária ${ }^{7}$ o biógrafo é levado a crer, mais uma vez pela experiência, que Ferreira de Castro "foi o construtor da sua própria personalidade literária" (BRASIL, 1961, p. 62) - personalidade profundamente marcada pela experiência de imigrante na Amazônia.

Os primeiros textos escritos por Castro, de fato, nascem quando esse era ainda adolescente, habitante do seringal. Todavia, as duas primeiras composições - Criminoso por ambição, novela que escreveu aos 14 anos; e Rugas sociais (romance publicado em folhetim) foram excluídas da lista de publicações pelo próprio autor, justamente por considerar que nelas a experiência sobrepujava o valor estético (cf. BRASIL, p. 29-32). Entre uma realidade pulsante, que lhe dava motivação para escrever, e a busca por inventar-se como ficcionista, o jovem lusitano, ao descartar tais textos, parece reconhecer que, ainda que seja tênue, há um contorno que dá formas diferentes à realidade e à estética.

O romance $A$ Selva foi publicado em 1930, nos anos posteriores à passagem do português pela Amazônia. Não obstante, cada nova edição traduzida para diversos idiomas, por intermédio dos paratextos (prefácios, comentários, orelhas, pórtico), não deixava de associar o arquivo do autor e a narrativa que chegava ao leitor de países europeus e da América. Essas produções, ligadas a uma crítica biográfica ingênua, acabaram criando uma tradição no modo como a crítica leu os arquivos e a ficção do autor. Em caso semelhante, a professora Eneida Maria de Souza, no livro Janelas indiscretas (2011), problematizando os modos como por muito tempo se leu a escrita biográfica de Pedro Nava, afirma:

Por se tratar de uma obra de teor memorialístico, a única maneira de ir
além dos dados biográficos aí narrados consistiu no procedimento
relativo à ficcionalização e teorização do que já havia sido registrado pelo
autor. Essa prática ensaística não pretende distorcer nem embelezar os
fatos narrados, mas interpretá-los segundo sua relação com o contexto e
com a ajuda de instrumental teórico exigido para tal. Ficcionalizar os
dados significa considerá-los como metáfora, ordená-los de modo
narrativo, sem que haja qualquer desvio em relação à "verdade" factual.
(2011, p. 11).

Tomando o mesmo argumento para pensar a obra castriana, é possível então, além de necessário, desconfiar do apelo factual de uma crítica biográfica tendenciosa que unifica obra e vida, desestabilizando o leitor comum. Para tal, torna-se necessário retornar à produção crítica, aos paratextos, na tentativa de relê-los, deixando mais aparentes os

\footnotetext{
7 Afirma Jaime Brasil: "Esse rapaz, cuja preparação literária era a bem dizer nula e não convivera em grandes centros com discípulos e amigos cultos que lhe servissem de estímulo e de guias, sentiu desde muito novo a ânsia de escrever para o público" (BRASIL, 1961, p. 29).
} 
processos discursivos que eles operam. Retomemos três paratextos que acompanharam o romance $A$ Selva e estão incluídos na biografia escrita por Jaime Brasil.

A primeira publicação do romance na Alemanha surge em 1932. Doutor Richard Bermann (nome literário de Arnold Hoellriegel), um turista que visitou a Amazônia, resolve traduzir $A$ Selva para o vernáculo de seu país. Junto com a obra, publica um prefácio, no qual escreve:

$\mathrm{Na}$ minha volta pelo interior do Amazonas, caiu-me nas mãos, por acaso, um livro português que finalmente quebra o silêncio sobre a selva verde. [...] O autor chama-se José Maria Ferreira de Castro [...]. O que descreve, com tanta realidade, no seu romance $A$ Selva, tudo isso ele viveu. Neste romance, Ferreira de Castro não descreve somente o inferno dos pesquisadores da borracha de uma forma para sempre inolvidável, mas também a majestosa natureza da floresta virgem, em toda a sua trágica beleza. Na sua obra, a selva do Amazonas foi vista, pela primeira vez, por um homem que não viajou, mas que viveu dentro dela própria. (1961, p. 108, grifos nossos).

Note-se que Bermann identifica-se com o escritor por terem, ambos, habitado a floresta. Contudo, o alemão concede a Castro maior domínio sobre a realidade, uma vez que o homem/escritor testemunhou o que narra no romance. Outro prefácio foi publicado em 1935, na América do Norte, por Charles A. Wagner, que escreve: “achei o romance de Castro, imensamente autobiográfico e capaz de ser o melhor dos produtos portugueses modernos, começava a entrar-me no fato, na pele, no coração, nos ossos, na medula e na consciência" (1961, p. 114, grifo nosso). Já o prefaciador norte-americano destaca as marcas da vida de Castro deixadas no romance, reconhecendo-o como uma escrita em que o eu margeia o texto ficcional.

$\mathrm{Na}$ Bélgica, um célebre crítico do país, o acadêmico Henri Liebrecht, além do prefácio que escreveu para $A$ Selva, publicou um extenso ensaio sobre Ferreira de Castro, no qual afirma: "foi preciso que um escritor português tivesse vivido na sua juventude a existência dos colonos e passasse longos meses no coração da floresta virgem, [...] para trazer os elementos e as impressões com os quais comporia A Selva, esse documentário" (1961, p. 128, grifo nosso). E continua: "se este livro saiu duma obsessão do autor, enfeitiçado pela floresta virgem e pelo imenso rio que a atravessa, ele soube traduði-la com uma força tal que ela se comunica ao seu leitor" (p. 128, grifo nosso). O discurso de Liebrecht opera um desdobramento da obra do autor na sua vida, tratando o romance como documento, como uma tradução da Amazônia, uma janela que se abre para o canteiro do látex. 
As notas dos prefaciadores, que são antes de tudo leitores, revelam um desconcerto perante a ficção e o real. Todos partem de um discurso que confere ao texto o estatuto de veracidade. Segundo Wander Melo Miranda (2009), quando se tem implicada uma relação autobiográfica e de ficção, é compreensível que a desestabilização se processe, uma vez que a fronteira entre fato e criação subjetivamente verdadeira é bastante tênue,

\begin{abstract}
podendo o grau de 'fingimento' de determinados textos ser tão variável que torna difícil a diferenciação entre uma autobiografia autêntica e uma composição já romanceada. Muitos romances em primeira pessoa podem "fingir" o relato verídico de uma experiência pessoal, sem que o leitor seja capaz de desfazer a ambiguidade entre a história concreta de um eu real, que remeteria ao autor, e a sua recriação metafórica em termos de invenção ficcional. (2009, p. 33)
\end{abstract}

Explica-se, portanto, o emaranhado entre um eu pessoa e um eu personagem, que intercala o romance e a biografia de Castro, uma tradição construída diacronicamente e que foi se intensificando em grande medida pela inserção de paratextos, que sempre acompanharam e acompanham as diversas traduções do romance.

Uma das leituras dos arquivos pessoais de Castro que mais chamou a atenção foi o livro de Abrahim Baze, intitulado Ferreira de Castro: um imigrante português na Amazônia. Chamou atenção por alguns motivos: primeiro, porque o autor apresenta um discurso que (aparentemente) ignora a distinção entre instâncias como ficção, História e biografia. Ao propor, como anuncia o título, fazer uma biografia do escritor, vai ao longo do texto entremeando história do ciclo da borracha, arquivo memorialístico e corporal de Castro e personagens do romance $A$ Selva. Outro motivo instigante é o fato de que a obra foi publicada no Brasil em 2005, sendo, portanto, muito recente no rol da crítica castriana. Vêse bem que a tradição de uma concepção ingênua da crítica acerca dos arquivos pessoais do escritor, vinculando a experiência do homem à obra, permanece. Em seu livro, Abrahim Baze passa da pura narrativa histórica às personagens do romance, sem sequer anunciar ao leitor que está tratando de ficção. Discurso intencional ou fruto de um desconhecimento (por parte do ensaísta) das diferenças entre o eu ficcionado e o eu vivido, o texto de Baze chega a causar uma confusão teórica, uma teia em que o leitor desavisado pode perder-se rapidamente.

A lembrar o trabalho de ficcionalização biográfica que Silviano Santiago tece no romance Em liberdade, poderia questionar-se, embora se possa deduzir que não foi a intenção, se o que Baze tentou fazer não foi o mesmo, uma vez que não fica claro se personagens do romance - como é o caso de Balbino, citado várias vezes -, são históricos 
ou literários. Além de colocar sobre o mesmo plano de análise personagens e pessoas, o biógrafo põe, sobre o mesmo plano, fatos históricos e enredo, como se pode observar no fragmento que se reporta à passagem do navio "Justo Chermont" pela cidade de Manaus:

Alguns passageiros, oriundos do Ceará, logo se juntaram a Ferreira de Castro fazendo muitos planos e prometendo desembarcar para conhecer Manaus.

Balbino, dominador, carrasco prepotente, lança logo ordens proibitivas, dizendo que ninguém poderia desembarcar. Com a proibição de Balbino, aumenta a força e a decisão do grupo ir a terra.

$[\ldots]$

Humilhado, cansado da obediência escravizadora, Ferreira de Castro mostra a sua força. Embora jovem, mas consciente das agruras vividas por todos, exclama em voz alta: - Eu desembarcarei! (2005, p. 50, grifos nossos).

Nota-se que o ensaísta não deixa claro se está se reportando a um episódio da vida de Castro ou ao episódio do romance que narra a passagem do navio por Manaus. O autor re(cria) falas que atribui a Ferreira de Castro, sem citar sequer as fontes que o possibilitaram escrever em discurso direto. Acerca desse conflito, isto é, entre a representação do discurso dos fatos e da ficção, é novamente a professora Eneida Maria de Souza que problematiza a chave interpretativa:

Ainda que determinada cena recriada na ficção remeta a um fato vivenciado pelo autor, deve-se distinguir entre a busca de provas e a confirmação de verdades atribuídas ao acontecimento, do modo como a situação foi metaforizada e deslocada pela ficção. O nome próprio do personagem, mesmo que faça referência a pessoas conhecidas do escritor, não impede que sua encenação embaralhe os dados e coloque a verdade biográfica em suspenso. (2011, p. 19-20).

Abrahim Baze, ao longo do seu ensaio, envolve-se na teia que costura ficção e biografia, operando com um método que não desembaraça tais categorias discursivas, além de buscar fatos históricos que comprovem episódios narrados no romance.

Ao final da biografia, o autor insere arquivos de algumas pessoas que ele associa a personagens de A Selva, identificando, após os nomes próprios, os nomes de personagens.

Em 1955, por ocasião do vigésimo quinto ano de aniversário do romance, Ferreira de Castro escreve e publica uma espécie de "carta ao leitor" intitulada "Pequena história de A Selva", que inseriu definitivamente no cenário dos paratextos o arquivo memorialístico e corporal do homem/escritor. A partir de então, ratificou-se o discurso híbrido entre ficção e biografia. Jaime Brasil, ao reportar-se a esse escrito, comenta: “um dos textos que não poderia deixar de figurar nesta Antologia, tanto pelo seu valor literário como por se tratar 
dum valioso documento autobiográfico, é Pequena História de A Selva” (BRASIL, p. 155). A assertiva do biógrafo põe em cena duas possibilidades de recepção do escrito: de um lado, como uma confissão do eu-pessoa, ou seja, uma exposição pública e verídica de um arquivo pessoal; e, de outro, como eu-personagem, isto é, como uma ficcionalização literária do eu. Por ora, pensa-se ser possível ler a composição de Castro como uma textualidade híbrida, que mobiliza o "gênero epistolar a serviço da ficção" (CAMPOS, 2010, p. 11). A esse respeito, Nathalia Campos pondera que "a carta pode apresentar-se como um 'sofisma afetivo', sendo capaz de provocar no inconsciente do leitor, sob a sensação de verdade, uma comoção que o simulacro - a literatura - encarrega-se de reproporcionar" (2010, p. 12). E continua:

a carta, talvez aquela que possa ser considerada a prática de arquivamento por excelência, sublinha a importância do escritor em questão [...] e quer garantir um acesso inequívoco e terminante ao sujeito, lugar onde se teria vista para paisagens profundas do eu, outras, irreveladas, normalmente inconfessáveis, que só e tão só no convívio epistolar encontram a ocasião de virem à luz. (p. 18).

Alinhado a esse pensamento, Gérard Genette, ao tratar de tipos paratextuais classificados como "prefácios autorais" - dos quais toma-se com exemplo "Pequena história de $A$ selva" - tece as seguintes considerações: 1) sua função principal seria garantir ao texto uma boa leitura; 2) levar o leitor a ler sua obra, mostrando por que e como; 3) atuar como mecanismo de valorização da obra; 4) afiançar mérito a si mesmo por meio da garantia de veracidade. Afirma o estudioso francês: “o único mérito que um autor pode atribuir-se por meio do prefácio, provavelmente porque depende mais da consciência do que do talento, é o da veracidade ou, pelo menos, de sinceridade, isto é, de esforço no sentido da veracidade" (GENETTE, 2009, p. 184). A composição de Ferreira de Castro que entremeia experiência pessoal e processo de construção literária cumpre, ao que se nota, as funções descritas por Genette. Assim, pela perspectiva do teórico, deve-se pensar o texto castriano não como um simples enunciado, mas como um ato de discurso ou, mais do que isso, um ato de discurso literariamente intencionado. É perceptível, nos textos apresentados anteriormente, o quanto o leitor aceita a veracidade agenciada pelo discurso contido em $A$ selva e nos paratextos autorais que o acompanham.

Passados mais de oitenta anos da primeira publicação do romance, tornou-se fato que, uma vez inseridos como paratextos, os arquivos de José Maria Ferreira de Castro impõem-se, frequentemente, como dados imprescindíveis à leitura de sua obra literária, 
inspirando verdadeiro culto (biográfico) em torno do autor. Não obstante, é preciso enfatizar que,

mesmo em sentido restrito, a autobiografia tende a assimilar técnicas e procedimentos estilísticos próprios da ficção. Isso evidencia o paradoxo da autobiografia literária, a qual pretende ser simultaneamente um discurso verídico e uma forma de arte, situando-se no centro da tensão entre transparência referencial e a pesquisa estética e estabelecendo uma gradação entre textos que vão da insipidez do curriculum vitae à complexa elaboração da pura poesia. (MIRANDA, 2009, p. 30).

O que interessou ao longo deste artigo não foi menosprezar o valor que os arquivos memorialísticos e corporais de Ferreira de Castro assumem na compreensão de sua obra, mas de trazer à consciência teórico-literária a necessidade de que o crítico entenda toda a produção, tanto biográfica quanto literária, como formas discursivas de dar-se a conhecer ao outro. Imprescindível, portanto, que se tenha em mente o risco permanente do deslizamento do campo ficcional para o (auto)biográfico, tendo em vista o seu revestir-se da livre invenção - metáfora tão bem representada pela mão que segura o pincel de Van Gogh, retratando-o tantas vezes e de formas várias. E aqui, volto ao retrato de Castro estampado na biografia que se encontra sobre a mesa e o vejo análogo aos autorretratos do pintor holandês.

\section{Referências}

BAZE, Abrahim. Ferreira de Castro: um imigrante português na Amazônia. Manaus: Valer, 2005.

BRASIL, Jaime. Ferreira de Castro: a obra e o homem. Lisboa: Editora Arcádia, 1961.

CAMPOS, Nathalia. A narrativa do eu: a carta como intriga biográfica e como gênero literário. In: SAID, Roberto; SANDRA, Nunes (orgs.). Margens teóricas: memória e acervos literários. Belo Horizonte: Editora UFMG, 2010. p. 11-23.

CASTRO, José $\mathrm{M}^{\mathrm{a}}$ Ferreira de. Pequena história de A Selva. In: A selva. 37. ed. Lisboa: Guimarães, 1989. p. 17-24.

CANDIDO, Antonio; CASTELO José Aderaldo. Presença da Literatura Brasileira: história e antologia. 5. ed. Rio de Janeiro: Bertrand Brasil,1992. 
EAGLETON, Terry. Teoria da literatura: uma introdução. Tradução Waltersin Dutra. 5. ed. São Paulo: Martins Fontes, 2003.

GENETTE, Gérard. Paratextos editoriais. Tradução Álvaro Faleiros. São Paulo: Ateliê Editorial, 2009.

MIRANDA, Wander Melo. A ilusão autobiográfica. In: Corpos escritos. 2. ed. São Paulo: EDUSP, 2009. p. 25-41.

SANTIAGO, Silviano. Em liberdade. São Paulo: Editora Perspectiva, 1970.

SOUZA, Eneida Maria de. Janelas indiscretas: ensaios de crítica biográfica. Belo Horizonte: Editora UFMG, 2011.

STEGAGNO-PICCHIO, Luciana. História da Literatura Brasileira. Tradução Pérola de Carvalho; Alice Kyoko. 2. ed. Rio de Janeiro: Nova Aguilar, 2004.

Artigo recebido em: 01 de Fevereiro de 2012.

Artigo aprovado em: 31 de Outubro de 2012. 